\title{
CHROMOSOME BEHAVIOR IN TRIPLOID PETUNIA HYBRIDS 1
}

\author{
Willatam Campbell Steere
}

(Received for publication October I, I93 I)

\section{INTRODUCTION}

During the summer of 1928 , several species and a large number of horticultural varieties of Petunia were grown at the Botanical Gardens of the University of Michigan, for cytological and genetical investigation. The seed was obtained from various commercial sources and through the kindness of a number of Botanical Gardens and individuals.

The large flowered forms commonly known as "California Giants," "Diener's Monsters," etc., were of especial interest, since they appeared to be typical gigas forms. Because of the unusually large and fleshy flowers and leaves, combined with the large stature of the plant, they were assumed to be tetraploids, since Vilmorin and Simonet (54) had reported that such types exist in the genus. Later in the season, the tetraploid nature of the gigas types was established.

With the possibility in mind of producing triploids, reciprocal crosses were made between tetraploid and diploid types, but very little seed was produced, and none germinated.

During the summer of 1929 , the reciprocal crosses were repeated between diploids and tetraploids on a larger scale than the previous year. A pure strain of $P$. axillaris (Lam.) BSP. (P. nyctaginiflora Juss.), which has white flowers and yellow pollen, was used as the diploid parent (Pl. XXIII, fig. 2). As parthenogenesis has occasionally been reported in the Solanaceae, strains of tetraploids with dark colored flowers and blue pollen were chosen as the other parent. From these crosses, large amounts of seed were secured, especially from the cross diploid of $\times$ tetraploid $\sigma^{7}$.

The $F_{1}$ plants of the reciprocal crosses were grown and examined during the summer of 1930. Unexpectedly large progenies were secured from the diploid $\% \times$ tetraploid $\sigma^{\top}$ cross, a total of 1348 plants resulting from the contents of about fifteen seed capsules. In each of two cultures there were nearly 500 plants, and the remaining cultures contained somewhat smaller numbers. Approximately half of these plants were intermediate in size between the two parents, while the rest resembled the diploid plant almost exactly in stature and habit. The flower color of each parent was represented in the progeny, as well as intermediate shades.

It was not believed likely that so many triploids could be obtained, and subsequent examination of random plants has shown that apparently they

${ }^{1}$ Papers from the Department of Botany, University of Michigan, number 365 . 
are normal diploids. They cannot have arisen parthenogenetically, but must have contained a certain number of chromosomes contributed by the pollen parent, as the resemblance in habit and flower color showed. Different proportions of each set of parental chromosomes were apparently present in these $F_{1}$ plants, since there was such a wide range of variation, especially as one of the parents ( $P$. axillaris) is known to be a pure strain. The cytology and genetics of this cross will be reported later.

\section{The Triploid Material}

The $\mathrm{F}_{3}$ generation from tetraploid o $\times$ diploid $\sigma^{\top}$ cross was quite different in appearance and chromosomal constitution from the progeny of the reciprocal, previously described. Out of a large amount of seed, only 16 plants appeared, belonging to two different cultures. By examination of the pollen mother cells of these plants in aceto-carmin they were all found to be triploids.

One of the cultures consisted of eleven plants which were the progeny of a tetraploid with deep red flowers and blue pollen, pollinated by $P$. axillaris. This group, hereafter designated as culture 264 , showed great variation among the plants, not only in color and size of flowers, but in growth habit and stature as well.

According to their appearance, these individuals fitted rather clearly into three classes. Five plants $(2,4,5,8$, I I) resembled the tetraploid in their large fleshy habit, although the flowers were not so massive. The flowers were of the same shape as those of the diploid parent, three being of the same color (white), and two were of a deep red-purple color (Pl. XXIII, fig. 5).

Four plants $(3,6,9,10)$, all very similar in appearance, seemed to show more of the paternal characters than the preceding class. The habit of the plants and the size and shape of the flowers were all very similar to those of the pollen parent, but the flowers, instead of being white, were reddish-purple with blue pollen (Pl. XXIII, fig. 4).

The last class consisted of two individuals $(I, 7)$ of an unexpected and unexplained character. Instead of being intermediate between the two parents in size and general appearance, these plants were almost exactly similar to the pollen parent, but very noticeably smaller, otherwise differing only in having blue pollen (P1. XXIII, fig. 3).

The other triploid culture consisted of five plants and was secured by pollinating a pink-flowered tetraploid (Pl. XXIII, fig. I) with pollen from $P$. axillaris. This group of plants will be referred to subsequently as culture 266. There was less variation among the individuals of this group than in the preceding one, and the plants resembled the tetraploid parent in size and general habit more than they did the diploid. One plant (4) was especially close to the tetraploid type in appearance, except that the flowers were somewhat smaller and light purple in color (Pl. XXIII, fig. 6). 
The remaining plants resembled $P$. axillaris in flower shape, but were considerably larger and more fleshy in all respects, and had blue pollen. Two plants $(3,5)$ had purple-pink flowers, whereas two had the white flowers characteristic of the diploid parent.

In addition to the sixteen triploid plants just described, the author was kindly permitted to study a group of nine triploid individuals in the cultures of Dr. E. E. Dale, who had also made the tetraploid $\times$ diploid crosses. These nine plants were also examined cytologically and found to be characteristic triploids. The whole group of twenty-five different triploids supplied abundant cytological material, upon which this paper is based.

All of the triploid plants were found to be self-fertile, and also to set seed when pollinated by either parent. Most triploids have been reported to be completely self-sterile, and sterility has come to be considered typical of them.

Cuttings made from each triploid plant are maintained at the University of Michigan Botanical Garden. Back crosses and progenies secured by self-pollination are being investigated.

\section{Methods}

For counts of somatic chromosomes, root tips and styles were fixed in Taylor's modification of Flemming's chrom-osmo-acetic mixture (5I), which was found to be superior to several acetic-alcohol fixatives tried at the same time. Most of the cytological studies were of microsporogenesis. The anthers were fixed as follows: Several terminal branches bearing flower buds were removed and kept fresh by wrapping in moist towelling. One anther from each flower bud was examined in aceto-carmin, and if satisfactory stages were found, the remaining anthers were fixed. Thus much labor was saved, since nearly all the fixed material exhibited the desired stages of meiosis. Immediately after being placed in the fixing solution the anthers were cut into small pieces with a sharp scalpel in order to facilitate rapid penetration.

The root tips, styles, and anthers were then dehydrated, cleared, and imbedded in paraffin. The series of mixtures of butyl and ethyl alcohols for dehydrating and clearing suggested by Zirkle (56) was tried and found to be perfectly satisfactory. Sections were cut sufficiently thick to include entire cells, and stained by Newton's gentian-violet and iodine method (39).

For permanent records of chromosome counts, smears were made. Many were fixed in Taylor's modification of Flemming's solution, and stained in gentian violet. Others were fixed and stained in aceto-carmin, dehydrated in glacial acetic acid and absolute alcohol mixtures, cleared in an equal mixture of xylene and absolute alcohol, and mounted in balsam. This method, as previously described (Steere, 50), is rapid and quite satisfactory for chromosome counts. 


\section{Cytological Results}

So far as known, the basic haploid number in the genus Petunia is seven, which has been found in all the pure species yet examined. This number has been reported for $P$. violacea Lind. (Ferguson, 9, I0; Skalinska and Cuchtman, 48; Malinowski, 34; Vilmorin and Simonet, 52; and others), $P$. axillaris (Lam.) BSP. ( $P$. nyctaginiflora Juss.) (Ferguson, Io), and $P$. Parodii Steere (Steere, 49). $P$. inflata Fries, which was also examined, showed seven pairs of chromosomes during the reduction division.

On account of its almost complete self-sterility, the true $P$. violacea is extremely hard to keep under cultivation, so that very few living specimens of the pure species are now in existence outside of their natural range.

The commercial $P$. "violacea," which includes the common garden types, has been derived from crosses among $P$. violacea, $P$. axillaris, and $P$. inflata, so that it is a composite of two or three species, certain characteristics of each appearing in varying degrees in different strains. A horticultural name, $P$. hybrida, has been applied with considerable aptness.

Seeds of $P$. "violacea" secured from various botanical gardens gave strains of $P$. hybrida, $P$. inflata, or other species. The author has not as yet been able to secure a satisfactory pure strain of $P$. violacea, even after a continued search. It is therefore strongly suspected that many of the studies of nominal " $P$. violacea" have actually concerned either a closely related species or a hybrid. The latter alternative is the more probable for the reports of irregular meiosis, such as non-reduction, the production of microcytes, and similar phenomena, since these are characteristic manifestations of hybridity. The reports of loose pairing or no pairing of the chromosomes also suggest a strongly heterozygous or hybrid condition. From descriptions of the material, $P$. hybrida can frequently be recognized as having been used.

Of the three pure species in the author's cultures, $P$. axillaris, $P$. inflata, and $P$. parodii, the first was selected for the production of triploids because of the very regular type of meiosis, the large size of plants and flowers, and the high degree of self-fertility. This species has also been kept in culture longer and was known to be relatively pure genetically.

\section{Cytology of the Diploid P. axillaris}

The somatic divisions in the root tips of $P$. axillaris are very regular, the I4 chromosomes being easily counted at metaphase (text fig. I, $A$ ). No great size differences among the chromosomes are evident, and no constrictions, satellites or other distinctive morphological characters were found.

Skalinska and Cuchtman (48) have reported that certain polymorphic races of $P$. "violacea" show great variability in the size and shape of the somatic chromosomes. They further found that satellite-like bodies are sometimes present in the tissues of zygomorphic flowers, and are lacking in 
normal flowers on the same plant. Malinowski (34) has investigated a similar race of $P$. "violacea" which has both large and small variegated flowers on the same plant, and reports that large chromosomes are found in the large flowers, and small ones in the small flowers. He concludes that "variegation is connected in Petunia with the size of the chromosomes."

These remarkable findings were not observed in $P$. axillaris, in which the behavior of the somatic chromosomes is very regular.
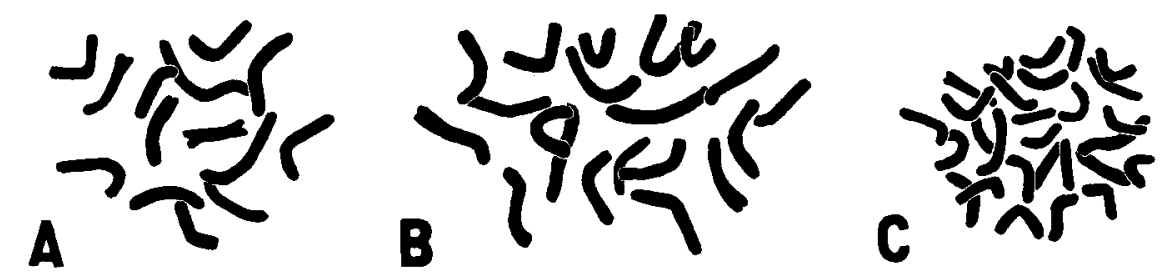

Text FIg. I. Somatic chromosomes from root-tip cells. A, Petunia axillaris ( $2 n=\mathrm{I} 4)$; $B$, Triploid form of $P$. hybrida $(2 n=2 \mathbf{r}) ; C$, Tetraploid $P$. hybrida $(2 n=28)$.

The regularity characteristic of mitosis continues throughout meiosis in $P$. axillaris. At diakinesis the chromosomes are closely paired, some side by side, others end to end, into seven gemini. The loose pairing ascribed to $P$. "violacea" by various workers was not observed in $P$. axillaris. The first division is very regular, and no instances of non-disjunction or unequal distribution of chromosomes were seen. The homotypic division is also regular and no abnormalities were seen in the large number of pollen mother cells examined. The tetrads are normal and without microcytes, and produce very few sterile pollen grains.

Matsuda (35) describes and figures a number of anomalous cytological conditions in $P$. "violacea," the most noteworthy of which are (I) the gemini at diakinesis are of ten joined together, sometimes into a complete ring, (2) in the early homotypic division the chromosomes may again become arranged in a ring, (3) during the homotypic division a darkly staining body "believed to be siderophile matter" was seen between the two spindles. These phenomena are undoubtedly caused by slow or faulty fixation. The anthers of Petunia species are protected by a heavy layer of cutin, which prevents the fixative from penetrating rapidly, so that the locules must be cut open in order to secure good fixation. The author has observed the same conditions described by Matsuda in anther locules which were not cut into during fixation, and into which the fixative penetrated very slowly. The remaining irregularities reported, as loose pairing of chromosomes, with the consequent appearance of univalents, lagging chromosomes, unequal distribution of chromosomes in either division, the formation of restitution nuclei, suppression of one or both divisions, with the production of monads, diads, triads, etc., are all believed to be due to the hybrid condition of the material. 


\section{Cytology of the Tetraploid P. hybrida}

The strains of gigas-type petunias which are sold under various trade names, such as "California Giants," "Diener's Monsters;" etc., arose spontaneously over 40 years ago. According to Bailey (I) they have been derived from one plant which appeared suddenly in the cultures of Mrs. Thomas Gould at Ventura, California, in I 888. Although this was probably not the first tetraploid mutation in Petunia, it was at least the first which received attention and which was cultivated as a new type.

Two other tetraploid mutants have appeared very recently. Kostoff (25) reports the spontaneous appearance of a larger plant in a culture of diploid plants. The mutational form blossomed over a week earlier than the other plants, and showed other physiological and morphological differences. Cytological examination of the root-tips showed 28 diploid chromosomes. The rediction division was found to be very irregular, and only about 50 percent of the pollen proved to be fertile. Furthermore, the plant was entirely self-sterile. When pollen from a diploid plant was used, however, seed was obtained. Among the progeny of this cross appeared sixteen plants which also were found to be tetraploids but which differed considerably from the maternal parent in appearance, and produced only about two percent of sterile pollen (Kostoff and Kendall, 26). The meiotic process was much less irregular in the $F_{1}$ tetraploid progeny, the chromosome complex having been stabilized in some way. Other aberrant types also appeared among the progeny of this cross.

Dermen (7) also reports the sudden appearance of a tetraploid Petunia $i_{n}$ a diploid population. It had very large flowers and leaves, but when self-pollinated, it gave both large-flowered and small-flowered tetraploids, showing that it was heterozygous for flower size.

Gigantism is often regarded as a consequence of the doubling of the chromatic material, but there is a possibility that concomitantly with doubling of the chromosomes there may sometimes be mutations of factors affecting size. The author has in his cultures tetraploids which are extremely large and fleshy as well as some which can be distinguished from diploids only with difficulty. On the other hand, diploid forms exist which almost exactly resemble tetraploids, and are hard to distinguish from them without careful examination. The large size of tetraploids is believed to be in part independent of the chromosome doubling, and so is a genetic rather than a physiologic expression.

Among the commercial tetraploid strains, a great deal of variation in cytological behavior was noticed. A few strains showed considerable aberration, the whole meiotic process being disturbed, much as in the tetraploid mutation described by Kostoff. In general, however, sporogenesis in the tetraploids is entirely regular, as in the diploid $P$. axillaris. This is to be expected, for although the tetraploid arose from a hybrid, the doubling of the chromosome sets provided a duplicate or homologue 
for each member of the set, so that complete pairing was possible. The same phenomenon was observed in hybrids between Brassica and Raphanus by Karpetschenko (2I), who found that even though meiosis in the original hybrid was very irregular, with complete lack of pairing of the chromosomes, unequal segregation, etc., the same process in tetraploid hybrids was quite regular, since the two homologous sets from each parent were present, and paired inter se.

\section{Cytology of the Triploid Hybrids}

The somatic chromosomes were counted in the root tips and styles of I6 triploid specimens, and each plant was found to have the expected number of $2 \mathrm{r}$. The mitotic divisions are very regular, and no abnormalities were observed in the distribution of the chromosomes. As in the other forms studied, no striking size or morphological differences were visible among them. The dissimilarity of appearance of root tip chromosomes and those found in the somatic tissues of the young flowers is worthy of note. The root tip chromosomes are longer, more slender, and show more definite differences in size and shape. The chromosomes in the meristematic tissue of the flower are much condensed, and show very little difference in size among them. (Compare text figure I with figure I of Plate XXIV.)

Meiosis was found to be very similar in all the individuals. The meiotic process is surprisingly regular, considering the unbalanced chromosome complement. A detailed study of the prophases was not made, although some stages were examined. Paired threads were sometimes seen, but three parallel threads were never observed.

At early diakinesis the chromosomes are regularly united into sets of three (Pl. XXIV, fig. 2). Although one or two of these trivalent chromosome complexes may break up during late diakinesis, there are usually seven trivalents at the heterotypic metaphase (Pl. XXIV, figs. 3-6). This normal organization of the total chromosome complement into trivalents is very unusual, and has hitherto been reported in very few plants. In the majority of triploids so far known, only a partial production of trivalent chromosomes has been reported. In only a few instances have triploids without any trivalents at all been reported, notably in hybrid forms, which show only bivalents and univalents at diakinesis.

Dermen (7) has recently reported upon triploidy in Petunia, but since two hybrid forms were used as parents, the cytological behavior of his triploids was much less regular. For example, he did not find a complete association of all the chromosomes into trivalents.

In the author's triploid petunias, the chromosomes making up the trivalents are united in different ways, straight chains of three being the most common union, showing that several sets of three are closely homologous. Commonly, the third member is attached at one point of union of a pair. Sometimes the third member is attached to both members of a separated pair, as though the terminal chromosomes of a chain of three 
had started to pair together. These and other variations are shown in Plate XXIV, figures 3-5. Apparently there is not much constancy as to the proportion of each kind of trivalent in different microsporocytes. This inconstancy of arrangement of the chromosomes into trivalents is well illustrated by a trisomic mutation under investigation in which the extra chromosome is found united in a number of ways with its two homologues.

Two chromosomes from each trivalent normally pass to one pole, and the third to the opposite pole (PI. XXIV, figs. 7-8). Distribution of single and paired chromosomes is entirely at random, so that the expected segregation of ten and eleven chromosomes generally occurs. No great size differences are apparent among the constituent members of any trivalent, so that the paternal and maternal chromosomes are apparently of the same size. Thus the chromosomes of the gigas or tetraploid type are concluded to have just as much chromatin as those of the diploid. The individual chromosomes are almost spherical or elliptical, and all of approximately the same size. No distinctive morphological characters are visible, although, as mentioned before, there is some variation in the type of connection between the three chromosomes in each set.

Counts are difficult during the first division, since the chromosomes are crowded together, and further, it is often difficult to distinguish between bivalents and univalents.

When the nuclear walls appear around the disc-shaped telophasic chromosome group, the individual chromosomes do not undergo a complete reorganization and form a spireme, but remain separate and distinct throughout the interkinetic period. They become gradually distributed throughout the new nuclear cavities, which grow larger and change in shape from hollow discs into hollow spheres (Pl. XXIV, figs. I2-13, Pl. $\mathrm{XXV}$, figs. I-2). The chromosomes parallel these changes in nuclear size and shape by very characteristic alterations in their appearance. The occasional pairs of chromosomes which arrived at the poles still intact, now disjoin, and the component parts become entirely distinct. The nuclei at this stage are very large and nearly fill the sporocyte (Pl. XXV, fig. I). That the interkinetic phase persists for a relatively long period is manifested by the large number of preparations which show this stage.

The individual chromosomes begin to exhibit signs of the coming homotypic division by a characteristic constriction at the center, and a change in shape. They assume, gradually, a dumb-bell form, or more rarely the form of a short-armed cross ( $\mathrm{Pl}$. XXV, figs. I-2). The large spherical nuclei begin to contract, crowding the chromosomes together again, but into a spherical group (fig. 3). This early prophase may easily be distinguished from the preceding telophase by the spherical nucleus and the peculiarly constricted chromosomes. The nuclear walls disappear and leave the homotypic chromosomes in two closely-packed groups on different sides of the cell (fig. 4). The spindles form rapidly and the chromosomes 
become oriented upon them (figs. 4-7). The two spindles may be parallel or at right angles to each other, or at an intermediate angle. The metaphase plates are very even and regular, with the exception of a few abnormalities which will be discussed later. The already partly split chromosomes complete the division and the two halves of each one pass very regularly to opposite poles (figs. 8-Io).

The telophasic chromosomes in well fixed material are always separate and distinct, and may easily be counted. New nuclear walls appear and the chromosomes become evenly distributed throughout the inclosed cavities (Pl. XXV, fig. II). They become smaller and somewhat indistinct, as the nuclear cavity enlarges. Separation of the cells of the tetrad is due entirely to progressive furrowing of the cytoplasm, as no visible cell plates are laid down during either division (fig. I2). By the time cleavage is completed and the cells have become entirely separated within the wall of the old pollen mother cell, the chromosomes have anastomosed and formed a nuclear reticulum. The chromatin becomes more and more indistinct, as the nuclear cavity increases in size, and by the time the pollen grains are mature, the nucleus is in a resting condition and very hard to stain satisfactorily.

Good preparations of the first somatic mitosis of the microspore were not secured, due to the large amount of stored food, and the sensitiveness of the cells to changes in osmotic pressure. This division was found to occur before the pollen grains are shed, however.

The phases through which the nucleolar material passes were not followed through meiosis and subsequent stages, because its affinity for gentian violet apparently disappears about the middle of prophase and does not reappear until the pollen grains are mature.

\section{Irregularities of the Triploid Plants}

Since the Petunia triploids are cytologically and genetically unbalanced, their meiotic stages show a certain amount of irregularity, but not so much as that reported for other triploids. There is less irregularity in the writer's than in Dermen's triploid petunias.

At diakinesis one or more of the trivalents may break up into a bivalent and a univalent, or into three univalents. Any separation at all is of rare enough occurrence so that it must be considered as abnormal. The univalents migrate irregularly to the poles, often lagging behind or preceding the main group of chromosomes. The bivalents may migrate entire to one pole, or the members may segregate regularly. During the anaphase of the heterotypic division, lagging chromosomes frequently appear ( $\mathrm{Pl}$. XXV, figs. IO-II). The most common cause of this type of irregularity is the passing to the poles of the terminal members of a chain of three chromosomes, leaving the central chromosome at the equator of the spindle. Such lagging chromosomes may become completely isolated and cut off in 
the cytoplasm, or they may finally migrate slowly to one pole or the other and become included in one of the daughter nuclei. They often divide prematurely, the half chromosomes going to the same or to different nuclei, or remaining on the spindle (figs. IO-II). Occasionally a bivalent chromosome is seen to lag (fig. II). In addition to disjoining, the constituent chromosomes frequently split and may either be segregated regularly or remain in a group as the nucleus of a small cell. During interkinesis, many of the chromosomes split prematurely, prior to the homotypic division. These divided chromosomes are easily recognized in late interkinesis by their spherical form and small size, and by the usual proximity of both halves (fig. 2).

Because of this early splitting, the sum of the chromosomes present in the second division metaphase plates is frequently more than $2 \mathrm{I}$, and may be as high as 26 (Pl. XXV, fig. 6). On the theoretical basis of chance distribution, there should be just as many plates of eleven chromosomes as plates of ten. On account of lagging and other irregularities causing chromosome loss, there should be a reduction in the number of plates of eleven, and an increase in plates of ten. It was observed, however, that plates of eleven are far in the majority, in spite of the chromosome loss, and plates of twelve are just as common as plates of ten, which presents a considerable deviation from the expected segregation (table I). Careful examination indicated that distribution of chromosomes in the first division is entirely according to the laws of probability, and the discrepancy in numbers of chromosomes in the second division is accounted for by precocious splitting of lagging and interkinetic chromosomes.

Table I. Counts of Metaphase II Plates in Triploid Petunias

\begin{tabular}{|c|c|c|c|c|c|c|c|}
\hline Number of chromosomes. & 7 & 8 & 9 & Io & I I & I 2 & I3 \\
\hline Number of plates......... 2 & 8 & 40 & 68 & 104 & I 44 & 104 & 22 \\
\hline
\end{tabular}

There are not as many irregularities during the homotypic division as in the heterotypic. The halves of the chromosomes which split prematurely may lag and disintegrate, or become small, separate nuclei (Pl. XXV, fig. Io). The chromosomes cut off in the cytoplasm during the first division continue their activity, dividing and forming small independent nuclei. These microcytes produced by isolated chromosomes and groups of chromosomes are common in the triploid material and are directly proportional in size to the number of chromosomes which they contain (fig. I3).

None of the major irregularities reported by other writers appeared, such as complete non-reduction, the formation of restitution nuclei, the union of the interkinetic nuclei, or the fusion of the two homotypic spindles. A very few giant pollen grains, apparently containing all 2 I chromosomes, were seen, but the abnormal processes leading to their production were not observed. The meiotic processes in these particular triploid petunias are even more regular than meiosis in certain types of diploid $P$. hybrida, such as the one reported by Matsuda. 


\section{Discussion and Conclusions}

The term triploid has been used in a narrow sense by some workers, and in a broad sense by others. Belling (2) has defined a triploid plant, in the narrow sense, as one having a chromosome complex made up of a number of sets of three homologous chromosomes. According to this interpretation, there must be three identical groups of chromosomes present in each triploid cell. It is to be expected, on the basis of a similar behavior in diploids, that at the reduction division, all of the chromosomes will become arranged into groups of three. This expectation is not usually realized, however, as such an association of all the chromosomes into trivalents has been reported for very few plants.

Belling has reported complete trivalency in Datura $(5)$, Canna $(2,4)$ and Hyacinthus (3). The same condition is described in the present paper in Petunia. It has also been described in two wild Japanese species of Lycoris, L. radiata Herb. and L. squamigera Maxim., by Inariyama (I8). All of these constant triploids or "autotriploids" display a certain amount of meiotic irregularity which often results in the fragmentation of some of the trivalent chromosomes into univalents and bivalents. In addition to these slight irregularities of the autotriploids, triploids in closely related varieties and forms of Canna (Tokugawa and Kuwada, 53), Hyacinthus (Darlington, 6), and Petunia (Dermen, 7) do not show complete trivalency. Apparently, then, the complete association of homologous chromosomes in triploids is rarely possible, and is the unusual thing. Darlington found, in Hyacinthus (6), that homology is not the only factor in the formation of trivalents, but that size also is important, since short chromosomes form trivalents much less frequently than long ones do.

By far the majority of the triploids which have yet been investigated have been found to diverge to a greater or less extent from the expected complete association into sets of three. Although most triploids display trivalent chromosomes at late diakinesis and at early metaphase of the heterotypic division, the proportion of trivalents may often be very small, as compared with the number of bivalent and univalent chromosomes. This erratic and variable production of trivalents is representative of nearly all triploids which have been reported.

The greatest possible deviation from the expected or autotriploid type is shown by those plants which form no trivalent chromosomes at all, but have only bivalent and univalent chromosomes. Most of the instances reported have been hybrids which acquired two sets of chromosomes from one parent and one set from the other, the two parents belonging to different species or even genera. Under such circumstances, there can be very little association of the chromosomes into trivalents, since they are only slightly or not at all homologous. The earliest and best known examples of this type were the Drosera hybrids secured by crossing D. rotundifolia $(n=10)$ with $D$. longifolia $(n=20)$ (Rosenberg, 45$)$. Rosenberg found no trivalents 
at all, but ten pairs and ten unpaired chromosomes. Similar behavior has been reported since in species hybrids of Rosa (Erlanson, 8), and Triticum (Kihara, 23; Sax, 47; Thompson, 52). Two sets, probably from one of the parents, pair off together, leaving the remaining set from the other parent as isolated univalents, which behave independently of the bivalents.

The application of the term triploid to these plants is believed to be fully justified, in spite of the differences in association and arrangement of their chromosomes, since there is a high degree of resemblance among them. They all possess an unbalanced chromosome complex, consisting of three sets of chromosomes, and consequently exhibit many meiotic irregularities, which result in the production of a large amount of sterile pollen. Further, they are usually sterile and somewhat larger than the normal diploid type.

It is believed, then, that the innate character of the triploid does not depend on whether or not the chromosomes are homologous, but simply on the fact that there are three sets present. Whereas, in general, the presence of trivalents is considered one of the distinguishing features of triploid plants, it cannot be taken as the sole criterion. It is concluded that our definition of a triploid plant should be made broader and more general, so that the term may include any plant which possesses three times the basic number of chromosomes characteristic of the genus, without regard to the degree of homology among the three sets as indicated by the number of trivalents.

Since there is such a gradual transition between complete association of all the chromosomes into trivalents, and the complete absence of chromosome aggregation, it is hardly possible to classify triploids on the basis of chromosome behavior, as is usually done. In an attempt to find some other means of classifying them, it was discovered than nearly all triploids can appropriately be placed in one of two groups, on the basis of maintenance of the triploid character.

In the first group belong all the triploid species and varieties which are able to maintain their unstable chromosome complex from generation to generation. Since irregular segregation and extinction of the type would naturally follow sexual reproduction, and since most triploids are sterile, multiplication must of necessity be by some asexual means, which is sometimes rather obscure.

Certain species and varieties belonging to this first class of triploids are able to maintain their triploid nature and consequent taxonomic individuality by various types of apomixis and the resulting production of seed from which new triploid individuals will arise. Rosenberg (46) found that a constant wild species of Hieracium, H. umbellatum, is triploid, and that the embryos in the seed which produce triploids arise from nucellar buds. Holmgren (I7) found similar phenomena in various naturally occurring species of Eupatorium and Erigeron. Most members of this group preserve their triple set of chromosomes by more obvious means of vegetative 
reproduction. Typical triploid species and varieties of this sort have been found in a large number of genera which multiply by bulbs, stolons, rhizomes, etc. They have been described in Iris (Kazao, 22), Rubus (Longley, 28), Rosa (Erlanson, 8), Tulipa (Newton and Darlington, 40), Hyacinthus (Belling, 3, 6), Narcissus (Nagao, 36), Canna (Belling, 2, 4; Tokugawa and Kuwada, 53), Hemerocallis (Belling, 4), Fragaria (Yarnell, 55), and others. In general, these triploids have appeared spontaneously, either in the natural state, or under cultivation, and are probably the result of natural or artificial hybridization.

The second and larger group of triploids is composed of the forms or races of preëxisting species which are not able to retain cytological and systematic individuality from generation to generation, since they do not habitually reproduce vegetatively. Some members of this group can be artificially propagated, however. Although a few examples are unstable wild triploid species, as those found in the genus Crataegus (Longley, 29), and in Prunus (Okabe, $4 \mathrm{I}$ ), most known triploids have arisen spontaneously as chromosome mutations among cultivated or experimental plants. Thus, Oenothera semi-gigas has appeared several times, and has been found to be characterized by $2 \mathrm{I}$ somatic chromosomes (Lutz, 32). Triploid mutations of Datura (Belling, 5), Zea (McClintock, 33; Randolph and McClintock, 44), Crepis (Navashin, 37), Nicotiana (Goodspeed, 16), tomato (Lesley, 27), Morus (Osawa, 43), and Primula (Ono, 42) have all arisen among normal diploid plants.

Other interesting triploids are those which have been produced experimentally as the result of crossing a tetraploid and a diploid race of the same species, as was done in the present investigation. Oenothera (Gates, I2; Geerts, 15) and Solanum (Jфrgensen, 20) triploids have been produced in the same way. The crossing of two species, either in the same or in different genera has also given rise to triploid hybrids, as reported for Triticum (Kihara, 23, 24; Sax, 47; Thompson, 52), Drosera (Rosenberg, 45), Citrus $\times$ Fortunella (Longley, 3I), and Zea $\times$ Euchlaena (Longley, 30).

These triploids of known origin are important, since through them desirable genetic characters may be interchanged between varieties or species with different chromosome numbers. Navaschin (37) found that crosses which normally were invariably unsuccessful would give fertile seed, if a triploid was used as the female parent. He found also, that by selfpollinating and crossing triploids, he was able to get higher polyploid forms, of still greater cytological and genetical interest. Also, considerable light is shed upon the origin of spontaneous triploid mutations by this type of triploid.

The sudden appearance of triploids among diploids has been the source of much speculation for two decades. Gates (14) has advanced the theory that triploid mutations are due to the union of two sperm nuclei with a single haploid egg. The only recorded observations that might be inter- 
preted to support this hypothesis are those of Nemec (38) on Gagea lutea and Ishikawa (I9) on Oenothera. That there is not much probability of such a phenomenon is evident, and the experimental evidence is slight. Concerning the observations of Nemec, Gates (I3) himself says: "Nemec believes that he has observed this (dispermy) in Gagea lutea, although it must be said that the evidence is not very conclusive." Ishikawa, however, observed and figured what was apparently the fusion of two sperm nuclei with a single egg nucleus.

Probably the best experimental evidence against Gates's theory has been produced by Navaschin (37), who found that triploids which arose spontaneously through the open pollination of Crepis capillaris contained a diploid capillaris complex, in addition to a foreign set of chromosomes. It is manifest that dispermy cannot have occurred here, but that an alternative theory is necessary. Navaschin's triploids have been produced through the normal fusion of two gametes, one haploid and the other diploid, the latter being the egg. It is very evident that triploids produced experimentally by crossing diploid and tetraploid races, as, for example, the writer's triploid Petunias, certainly might have arisen only by the fusion of a diploid and a haploid gamete.

That gametes with the somatic number of chromosomes are often produced has long been known. Hybrid plants, as described earlier, are frequently characterized by irregular meiosis, and produce, as a result, a certain number of diploid and other non-typical gametes. Under the stimulation of extremes of temperature or other abnormal physiological conditions, nearly any plant may be induced to produce diploid or polyploid gametes. The production of such gametes has been reported in a large number of species. By subjecting buds from the parent plant, as well as seeds and seedlings, to X-rays, Goodspeed (16) produced both triploid and tetraploid plants in Nicotiana tabacum. The spontaneous appearance of polyploid types in culture has frequently been correlated with unfavorable physiological conditions which were responsible for the production of irregular gametes.

Many attempts have been made to produce triploids by pollinating diploids with pollen from tetraploids. In the few instances in which the cross was successful, diploid plants have almost invariably resulted, as the author found. Apparently the only exception is that of Dermen (7), who secured triploids by the diploid $\& \times$ tetraploid $\sigma^{7}$ cross. Except for this one instance, all of the induced triploids have resulted from the cross tetraploid $q \times$ diploid $\sigma$. It is probable, then, that whereas a diploid sperm nucleus may rarely function, the diploid chromosome set of a triploid is almost always derived from the egg. Some objections have been raised concerning the possibility of fertilization of a diploid egg. Navaschin has shown, however, that in Crepis diploid eggs are capable of being fertilized as well as haploid ones, and that even higher polyploid egg cells are perfectly 
functional. Triploid, tetraploid, pentaploid, and heptaploid plants were all found in the immediate progeny of triploids.

The majority of triploids, then, and probably all which have arisen spontaneously, owe their existence to the fertilization of a diploid egg by a haploid sperm nucleus.

\title{
SUMmaRY
}

I. The tetraploid nature of the giant-flowered races of Petunia hybrida has been confirmed.

2. Reciprocal crosses were made between a tetraploid race of $P$. hybrida $(n=14)$ with colored flowers and a diploid species, P. axillaris $(n=7)$, which has white flowers and yellow pollen.

3. The diploid $\& \times$ tetraploid $\sigma^{7}$ cross produced normal diploids which combined characters from both parents.

4. Sixteen triploid plants resulted from the tetraploid of $\times$ diploid $\sigma^{7}$ cross, each with 2 I somatic chromosomes.

5. The triploid progeny were about intermediate between the two parents in size and habit, although two, of similar appearance, were noticeably smaller than either parent.

6. At the reduction division, the triploids normally show a complete association of all the chromosomes into sets of three.

7. The first and second divisions of meiosis are very regular, the only common irregularity being lagging of chromosomes. None of the extreme irregularity described for other triploids was seen.

8. A characteristic idiosyncrasy is the premature splitting of chromosomes during interkinesis. As a result, there is frequently an apparent excess of chromosomes at the homotypic division.

9. A considerable part of the pollen in the triploids is sterile, partly due to microcytes arising from chromosomes which lagged or became isolated during meiosis, and partly to cells which do not contain a complete or functional set of chromosomes.

Io. A classification of triploids on the basis of maintenance of the triploid character rather than upon the degree of chromosome association into trivalents is suggested.

II. It is concluded, from the results of the present investigation and from others, that triploids, with very few exceptions, have arisen from the union of a diploid egg with a haploid sperm nucleus.

The author wishes to express his appreciation of the greenhouse and garden facilities placed at his service by Professor H. H. Bartlett.

\author{
Botany Department, \\ UNIVERSity OF Michigan, \\ ANn Arbor, Michigan
}




\section{LITERATURE CITED}

I. Bailey, L. H. Cyclopedia of American horticulture. 3: 1285. I9I0. New York.

2. Belling, J. The behavior of homologous chromosomes in a triploid Canna. Proc Nat. Acad. Sci. 7: 197-20I. I92I.

3. - Homologous and similar chromosomes in diploid and triploid hyacinths. Genetics I0: 59-7I. I925.

4. - Chromosomes of Canna and of Hemerocallis. Jour. Heredity 16: $465-466$. I925.

5. Belling, J., and A. F. Blakeslee. The assortment of chromosomes in triploid daturas. Amer. Nat. 56:339-346. 1922.

6. Darlington, C. D. Meiosis in polyploids. II. Aneuploid hyacinths. Jour. Genetics 2I: $17-56$. 1929.

7. Dermen, H. Polyploidy in Petunia. Amer. Jour. Bot. 18: 250-261. 1931.

8. Erlanson, Eileen W. Cytological conditions and evidences for hybridity in North American wild roses. Bot. Gaz. 87: 443-506. 1929.

9. Ferguson, Margaret C. Preliminary announcement of a cytological and a genetical study of Petunia. Anat. Record 29: I37. I924.

Io. - - A cytological and genetical study of Petunia. Bull. Torrey Bot. Club 54: 657664. 1928.

I I. Gairdner, A. E. Campanula persicifolia and its tetraploid form; "Telham Beauty." Jour. Genetics I6: 34I-35I. I926.

I2. Gates, R. R. The behavior of chromosomes in Oenothera lata $\times$ O. gigas. Bot. Gaz. 48: 179-199. I909.

I3. - The mutation factor in evolution, with particular reference to Oenothera. 353 pp. 1915. London.

I4. - Polyploidy. British Jour. Exp. Biol. I: I 53-I82. I924.

I5. Geerts, J. M. Cytologische Untersuchungen einiger Bastarde von Oenothera gigas. Ber. Deutsch. Bot. Ges. 29: I60-I66. I9I I.

I6. Goodspeed, T. H. Occurrence of triploid and tetraploid individuals in X-ray progenies of Nicotiana tabacum. Univ. California Publ. Bot. Ir: 299-308. I930.

I7. Holmgren, I. Zytologische Studien über die Fortpflanzung bei den Gattungen Erigeron und Eupatorium. Kungl. Svensk. Vetenskaps. Handl. 59: I-I18. I9I9.

18. Inariyama, S. Cytological studies in the genus Lycoris. (Preliminary notes). Bot. Mag. Tokyo 45: I I-26. I93I.

I9. Ishikawa, M. Studies on the embryo-sac and fertilization in Oenothera. Annals Bot. 32: 279-3 7 . I9I8.

20. Jørgensen, C. A. The experimental formation of heteroploid plants in the genus Solanum. Jour. Genetics 19: I33-210. 1928.

21. Karpetschenko, G. D. Polyploid hybrids of Raphanus sativus L. $\times$ Brassica oleracea L. Zeitschr. Indukt. Abstamm. Vererbungsl. 48: 1 -85 . 1928.

22. Kazao, N. Cytological studies on Iris. Sci. Rep. Tohoku Imp. Univ. Biol. IV, 4: 55I-556. 1929.

23. Kihara, H. Cytologische und genetische Studien bei wichtigen Getreidearten mit besonderer Rucksicht auf das Verhalten des Chromosomen und die Sterilität in den Bastarden. Mem. Col. Sci. Kyoto. Imp. Univ., Ser. B, I: I-200. 1924.

24. - and I. Nishiyama. New aspects of chromosome behavior in pollen mother cells of tri-, tetra-, and pentaploid wheat hybrids. Bot. Mag. Tokyo 42:221-23I. I928.

25. Kostoff, D. Eine tetraploide Petunia. Zeitschr. Zellforsch. Mikrosk. Anat. 1o: 783786. 1930.

26. —-, and J. Kendall. Studies on certain Petunia aberrants. Jour. Genetics 24: I65I78. I93I.

27. Lesley, Margaret M. Maturation in diploid and triploid tomatoes. Genetics II: 267-279. 1926. 
28. Longley, A. E. Cytological studies in the genus Rubus. Amer. Jour. Bot. II: 249-282. I924.

29. - Cytological studies in the genus Crataegus. Amer. Jour. Bot. Ir: 295-3I7.

30. I924. Chromosomes in maize and maize relatives. Jour. Agr. Res. 28: 673-68r. 1924.

31. - Triploid citrus. Jour. Washington Acad. Sci. 16:543-545. 1926.

32. Lutz, A. Triploid mutants in Oenothera. Biol. Centralbl. 32: 385-435. I9I2.

33. McClintock, Barbara. A cytological and genetical study of triploid maize. Genetics 14: I 80-222. 1929.

34. Malinowski, E. Variegation and chromosomes in Petunia. Jour. Heredity I9: 521526. 1928.

35. Matsuda, H. On the origin of big pollen grains with an abnormal number of chromosomes. La Cellule 38: 213-243. I928.

36. Nagao, S. Karyological studies of the Narcissus plant. I. Somatic chromosome numbers of some garden varieties and some meiotic phases of a triploid variety. Mem. Col. Sci. Kyoto Imp. Univ. B, 4: 175-I98. 1929.

37. Navashin, M. Studies on polyploidy. I. Cytological investigations on triploidy in Crepis. Univ. California Publ. Agr. Sci. 2: 377-400. 1929.

38. Nemec, B. Ueber die Befruchtung bei Gagea. Bull. Int. Acad. Sci. Bohème I : I - I7. 1912.

39. Newton, W. C. F. Chromosome studies in Tulipa and some related genera. Jour. Linn. Soc. Bot. $47: 346.1927$.

40. - and C. D. Darlington. Meiosis in polyploids. I. Triploid and pentaploid tulips. Jour. Genetics 2 I : I-I 5. I 929.

4I. Okabe, S. Zur Cytologie der Gattung Prunus, Sci. Rep. Tohoku Imp. Univ. Biol. IV, 3: 733. 1928 .

42. Ono, T. Reducing division in triploid Primula. (A preliminary note). Bot. Mag. Tokyo 4I: 601 -604. 1927.

43. Osawa, I. Cytological and experimental studies in Morus, with special reference to triploid mutants. Bull. Imp. Ser. Exp. Sta. Tokyo I: 318-37o. I920.

44. Randolph, L., and Barbara McClintock. Polyploidy in Zea mays. Amer. Nat. 6o: 99. I926.

45. Rosenberg, 0 . Cytologische und morphologische Studien an Drosera longifolia $X$ rotundifolia. Kungl. Svensk. Vetensk. Handl. 43:3-64. 1909.

46. ——. Die Reduktionsteilung und ihre Degeneration in Hieracium. Svensk. Bot. Tidskr. II : 145-206. 1917.

47. Sax, K. Sterility in wheat hybrids. II. Chromosome behavior in partially sterile hybrids. Genetics 7: 513-552. 1922.

48. Skalinska, M., and S. Cuchtman. Karyologische Analyse einen polymorphen Rasse von Petunia violacea. Biblioth. Univ. Lib. Poland 1927: 3-23. 1927.

49. Steere, W. C. Petunia Parodii, a new species of the subgenus Pseudonicotiana from Argentina. Papers Michigan Acad. Sci. Arts Let. 13: 213-215. 1930.

50. —. A new and rapid method for making permanent aceto-carmin smears. Stain Technol. 6: 107-III. I931.

51. Taylor, W. R. General botanical microtechnique. (In: Handbook of microscopical technique, Ed. by C. E. McClung. I929. New York.)

52. Thompson, W. P. Chromosome behavior in triploid wheat hybrids. Jour. Genetics I7: 43-48. 1926.

53. Tokugawa, Y., and Y. Kuwada. Cytological studies on some garden varieties of Canna. Jap. Jour. Bot. 2: I57-173. I924.

54. Vilmorin, R. de, and M. Simonet. Variations du nombre des chromosomes chez quelques solanées. Compt. Rend. Acad. Sci. Paris 184: 164-I66. 1927.

55. Yarnell, S. H. Meiosis in a triploid Fragaria. Proc. Nat. Acad. Sci. 15: 843-844. I929. 


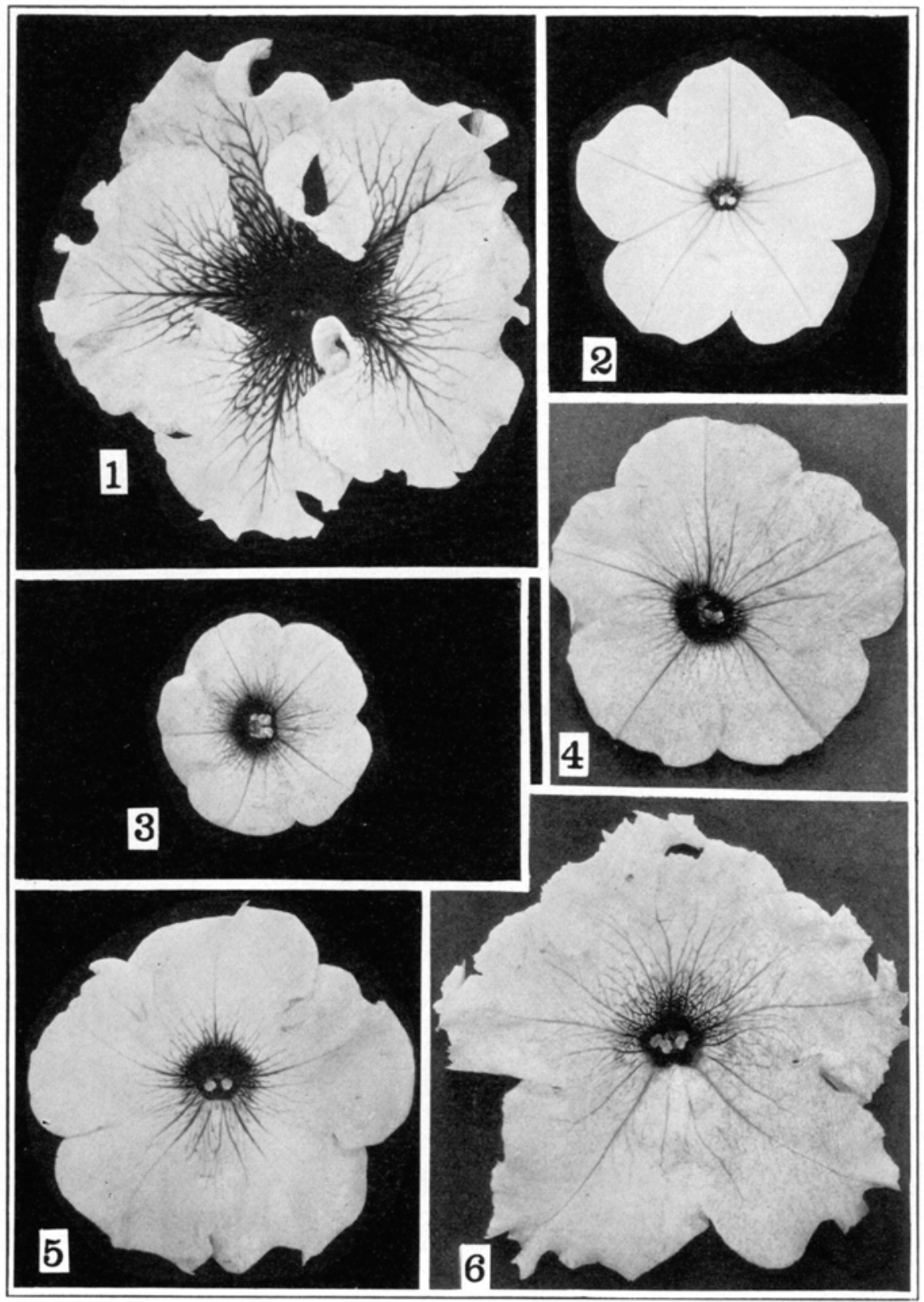

Steere: Petunia Chromosomes 

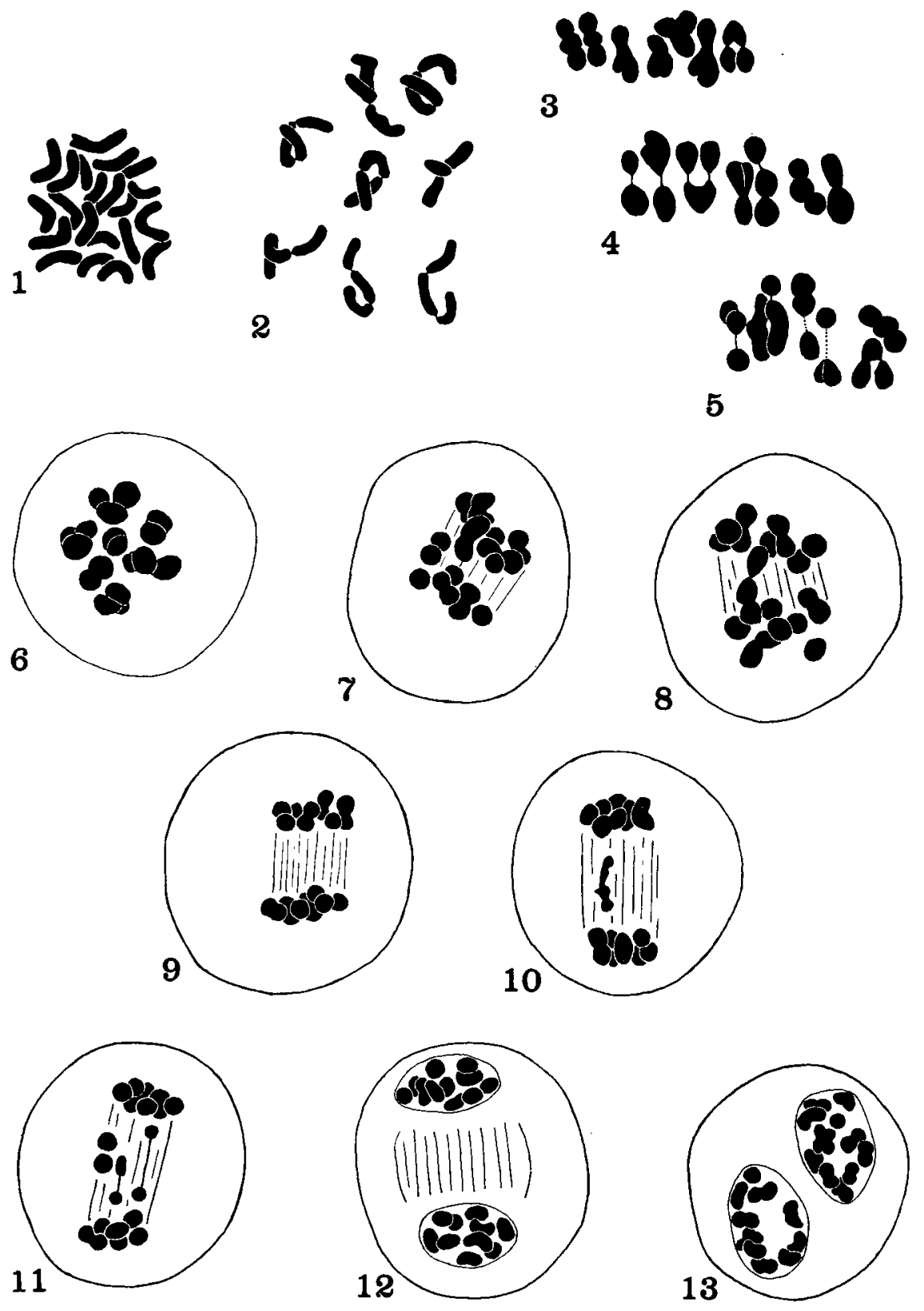

Steere: Petunia Chromosomes 

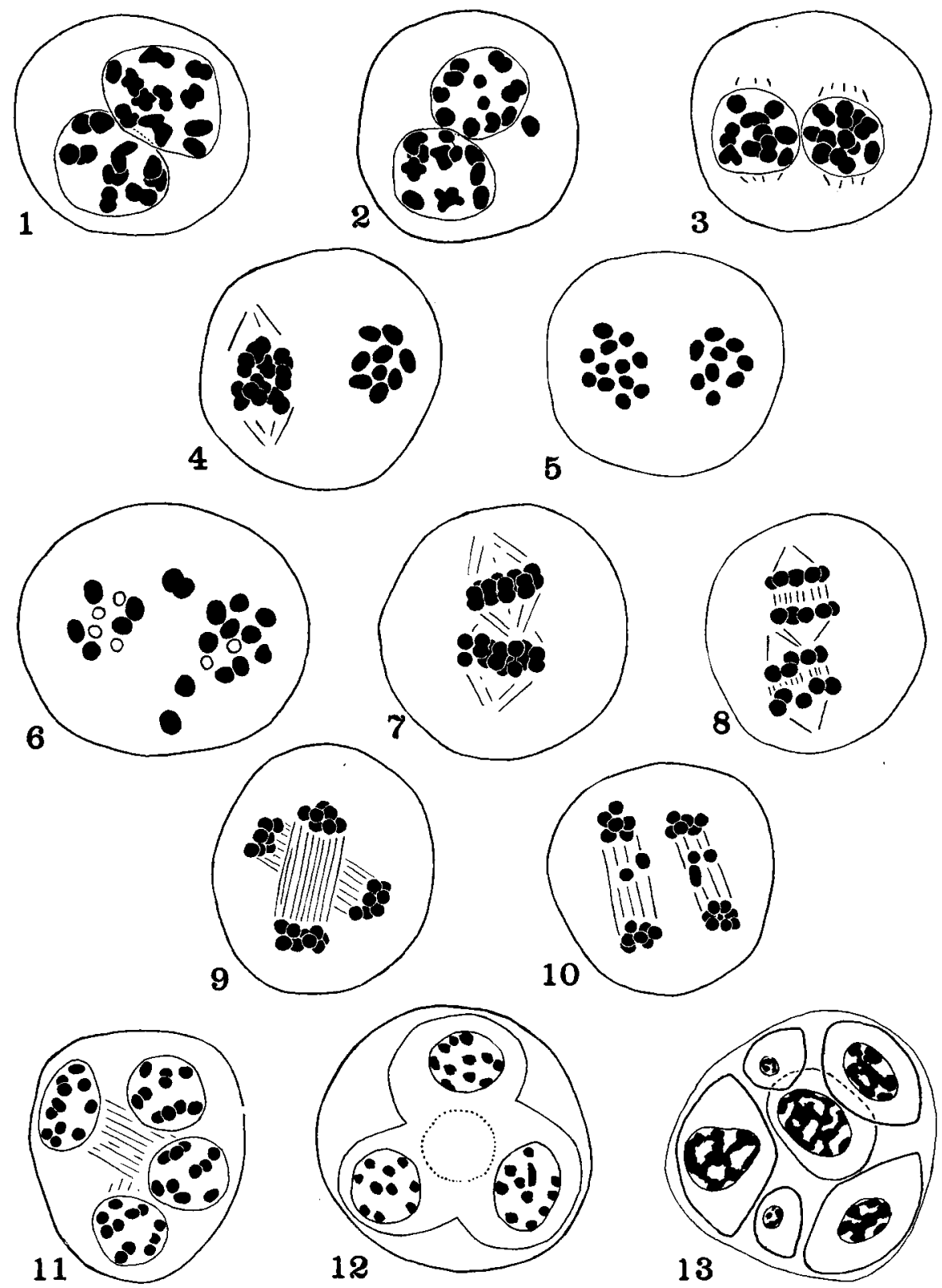

Steere: Petunia Chromosomes 
56. Zirkle, C. The use of N-butyl alcohol in dehydrating woody tissue for paraffin embedding. Science 7I: $103-104 . \quad$ I930.

\section{DESCRIPTION OF PLATES}

\section{Plate XXIII}

FIG. I. Pink flower from tetraploid parent of culture 266.*

FIG. 2. Flower from Petunia axillaris, the pollen parent of all the triploid plants.

FIG. 3. White flower from triploid plant 264-I. It is smaller than the flowers of either parent.

FIG. 4. Reddish-purple flower from triploid plant $264-10 .^{*}$

FIG. 5. White flower from triploid plant 264-5. parent.

FIG. 6. Lavender flower from triploid plant $266-4$, showing resemblance to tetraploid

* Due to the use of panchromatic film, the pink and reddish flowers appear quite light colored in the photographs.

\section{Plate XXIV}

Cytology of the triploids

FIG. I. Somatic chromosomes from nucellar tissue of ovule $(2 n=2 \mathrm{I})$.

FIG. 2. Various types of chromosome association at diakinesis, taken from several different cells.

FIGS. $3^{-5}$. Side views of the chromosome complements of individual cells, at metaphase and early anaphase of the heterotypic division, to show the complete association of all the chromosomes into trivalents.

FIG. 6. Polar view of the heterotypic metaphase, to show the seven trivalents.

FIGs. 7-8. Anaphase of the heterotypic division, showing disjunction of the trivalent chromosomes.

FIG. 9. Late heterotypic anaphase to show the normal condition of regular chromosome distribution.

FIG. Io. Late anaphase, showing lagging bivalent chromosome in which the component parts are disjoining and each one is splitting.

FIG. II. Late anaphase, showing two lagging univalent chromosomes which are splitting, and one lagging bivalent, the parts of which are disjoining.

FIG. 12. Telophase of the heterotypic division.

FIG. I3. Early interkinesis, to show the shape of the nuclei and chromosomes.

FIG. I. Interkinetic nuclei.

\section{Plate XXV}

FIG. 2. Late interkinesis, showing chromosomes which have split prematurely.

FIG. 3. Prophase of the homotypic division. The spindles are beginning to appear.

FIG. 4. Late homotypic prophase, showing a side view of one spindle and a polar view of the other.

FIG. 5. Homotypic metaphase, polar view, showing unequal numbers of chromosomes on each plate.

FIG. 6. Homotypic metaphase, polar view, to show chromosomes which have split prematurely and chromosomes which have become separated from the nuclei in earlier stages.

FIG. 7. Side view of the homotypic spindles at metaphase.

FIGS. 8-9. Successive stages in the homotypic anaphase, to show the regularity of chromosome distribution.

FIG. Io. Late homotypic anaphase, showing chromosomes lagging on the spindles.

F1G. II. Telophase of the homotypic division.

FIG. I2. Cleavage of the pollen mother cell into pollen grains by progressive furrowing.

FIG. 13. A hexad, the supernumerary pollen grains being due to chromosomes or groups of chromosomes cut off in the cytoplasm following either of the meiotic divisions. 